\title{
ESTÁGIOS NA FORMAÇÃO DE PROFESSORES (AS) NA AMAZÔNIA MARAJOARA: VIVÊNCIAS E EXPERIÊNCIAS DO CURSO DE PEDAGOGIA DO CAMPUS UNIVERSITÁRIO DO MARAJÓ - BREVES
}

\author{
Sônia Maria Pereira do Amaral \\ Universidade Federal do Pará (UFPA), Marajó-Breves, Pará, Brasil
}

\begin{abstract}
Resumo: O presente artigo tem como objetivo apresentar experiências de como se desenvolvem os estágios obrigatórios no curso de licenciatura em Pedagogia da Universidade Federal do Pará, Campus Universitário do Marajó-Breves. Caracterizase como uma pesquisa de base qualitativa. Como base teórica para as análises elegemos os estudos de Pimenta e Lima (2011), Franco (2012), Ghedin et al. (2015). Os (as) estudantes que fazem parte desse Campus são de diferentes municípios do Marajó, moradores do meio urbano e rural (ribeirinhos), o que faz com que os estágios se tornem grandes desafios, tanto para os (as) acadêmicos (as), quanto para os (as) professores (as), orientadores (as). Entretanto, os resultados apresentados indicam que os trabalhos realizados - entre ruas, rios e florestas - caminham na perspectiva de estágios como fonte de pesquisa, auxiliando na formação de professores (as) autônomos (as) e reflexivos (as) sobre e a partir da sua realidade sociocultural e educacional.
\end{abstract}

Palavras-chave: Estágios. Formação docente. Experiências. Marajó.

INTRODUÇÃO

A formação de professores (as) é um campo de múltiplas faces e uma delas encontra-se no estágio curricular, que é componente obrigatório nos cursos de licenciaturas. Na atual legislação - Resolução no 2, do Conselho Nacional de Educação de $1{ }^{\circ}$ de julho de 2015 - os cursos deverão ter no mínimo 400 horas dedicadas ao estágio supervisionado na área de formação e atuação na educação básica; entretanto, apesar de sua relevância na formação teórico-prática do(a) professor(a), o estágio ainda traz muitas inquietações sobre os seus modos de produção, ora pensado como mais um crédito a ser cumprido no curso, ora como um lugar de reflexão e construção de identidades docentes.

Nesse emaranhado de significados vamos construindo as mais diversas experiências nesse campo do saber. É a partir delas que nos propusemos a produzir o presente artigo, que tem como objetivo apresentar nossas experiências com os estágios obrigatórios no Curso de licenciatura em Pedagogia da Universidade Federal do Pará UFPA, Faculdade de Educação e Ciências Humanas do Campus Universitário do MarajóBreves (CUMB) -, onde atuamos como professora das disciplinas Práticas Pedagógicas e Estágios Supervisionados há 10 (dez) anos. 
O ponto de partida para este trabalho vai ao encontro do conceito de estágio apresentado por Ghedin et al. (2015), ao afirmá-lo como articulador da teoria-prática, formador da dimensão científica/técnica, política, ética e estética do futuro professor, local da construção da identidade profissional docente.

Nossos (as) interlocutores (as) são os (as) estudantes do curso de pedagogia, aqueles (as) que só conhecem a escola na condição de estudantes e que fazem do estágio seu ritual de passagem (PIMENTA e LIMA, 2011) para assumir a profissão e aqueles (as) que já atuam na profissão, mas que precisam dessa experiência como formação contínua, como espaço de reflexão de suas práticas, local para superação de desafios e produção de novos conhecimentos.

O artigo é composto por nossas experiências como professora de práticas de ensino e estágio supervisionado, das análises dos diários de estágios dos (as) discentes e dos relatórios e artigos, escritos como sistematização das atividades desenvolvidas nos diferentes estágios em ambientes escolares.

Na primeira seção, fazemos uma rápida abordagem sobre o Campus de Breves e seu papel de referência na formação de professores (as) no Marajó. Na segunda seção, endereçamos nossas discussões para as experiências vivenciadas no e com o curso ao longo da última década, trazendo os desafios e as conquistas diante desta atividade teórico-prática que vai adquirindo diferentes significações ao longo de cada estágio desenvolvido para, enfim, contribuir com a formação de identidades profissionais.

\section{O CAMPUS UNIVERSITÁRIO DO MARAJÓ - BREVES E A FORMAÇÃO DE PROFESSORES (AS)}

A formação de professores (as) no ensino superior no Marajó, por meio da Universidade Federal do Pará - UFPA, vem se consolidando em dois municípios, um que fica do lado do Marajó dos Campos', Soure; e o outro, no Marajó das Florestas; Breves², que é de onde falaremos neste artigo.

Até os anos 90 do século $X X$ os municípios ${ }^{3}$ do arquipélago marajoara, assim como outros pequenos municípios do Brasil (guardadas as diferenças regionais), tinham em seus quadros um grande número de professores (as) classificados (as) como leigos (as), por não terem a formação exigida por lei para atuar na educação - (Lei de Diretrizes e Bases da Educação Nacional - 9394/96, Art. 62, exige a formação mínima a oferecida em nível médio, na modalidade normal). Mesmo assim, esses (as) professores (as), eram responsáveis por turmas de educação infantil e dos anos iniciais do ensino fundamental, no meio urbano e com maior incidência no meio rural, onde se concentra o maior número de escolas municipais e de turmas, antes denominadas multisseriadas ${ }^{4}$, hoje multianos.

Há casos, de ex-alunos(as) nossos(as), que iniciaram suas atividades tendo cursado até a $3^{\mathrm{a}}$ série $\left(4^{\circ} \mathrm{ano}\right)$ do ensino fundamental, mas que foram contratados(as) pelo município para trabalhar no meio rural - escolas do campo, nas turmas multisseriadas, que congregavam crianças de $1^{\text {a }}$ a $4^{\text {a }}$ séries (atualmente, a primeira etapa do ensino fundamental de 9 anos) -, sendo assim suas práticas pedagógicas não vinham fundamentadas a partir de estágios de um curso de formação, mas pelos saberes das experiências de estudantes, das vivências com seus(suas) professores(as) e, em particular, as construídas no cotidiano, em serviço. 
AMARAL, S. M. P. do

Com o processo de interiorização da Universidade Federal do Pará, nos anos 90, Breves passou a receber cursos de licenciatura: em 1990, História; 1993, Geografia e Matemática; e em 1995, História e Pedagogia, sendo esses cursos oriundos das Faculdades localizadas na capital Belém/Pará. No ano de 1995, Breves tornou-se núcleo do Campus de Soure. A partir daquele ano, o núcleo de Breves passou a ofertar cursos de licenciaturas em anos alternados. No ano de 2009, o núcleo tornou-se Campus Universitário do MarajóBreves (CUMB), por meio da aprovação do novo Estatuto e Regimento Geral da UFPA, consolidando quatro Faculdades: Ciências Naturais, Letras, Matemática e Pedagogia, todas com docentes efetivos do quadro da UFPA.

Na formação de professores (as), por ser o CUMB considerado como polo de formação de professores no Marajó, em 2010 assumiu a coordenação de cursos que chegaram por meio do Plano Nacional de Formação de Professores da Educação Básica - PARFOR. De 2009 a 2017 através do PARFOR ofertou-se os cursos: Ciências Naturais, Biologia, Física, Química, Matemática, Pedagogia, Ciências Sociais, Letras-Português, Letras-Inglês, Letras-Espanhol, História, Geografia, Educação Física e Teatro. Também coordenou turmas em Ponta de Pedras, São Sebastião da Boa Vista, Portel e Melgaço (AMARAL, 2018, p. 46).

Conforme pode ser analisado, o CUMB se tornou referência em formação de professores (as) no Marajó, pois os alunos (as) chegavam de todos os lugares, até mesmo de outros estados brasileiros para cursar uma licenciatura. As primeiras turmas eram verdadeiras miscelâneas culturais, o que não deixou de ser, mas com menos intensidade. Mesmo assim, não é difícil encontrar uma turma que tenha em sua formação pessoas de pelo menos seis municípios diferentes, sejam do mesmo Estado ou de outros, sem contar que, os que são do mesmo município, nem sempre moram no meio urbano, muitos vêm de pequenos vilarejos do meio rural, portanto têm experiências culturais diferenciadas.

Essa referência foi feita aos (às) alunos (as) que entraram por meio de processos seletivos da UFP. Entretanto, a partir do ano de 2010, tivemos uma demanda de formação ainda maior, desta vez de professores (as) que tornaram-se acadêmicos (as), através do PARFOR que foi, e continua sendo um Plano que muito tem contribuído para a formação de professores (as) desse arquipélago, pois, como analisamos anteriormente, muitos (as) deles/delas estavam sem estudar há anos, alguns (mas) há pelo menos 15, 18 anos sem contato direto com uma sala de aula na condição de discentes.

A maioria dos (as) professores (as) que trabalharam nessas turmas é do quadro de professores do Magistério superior da UFPA - com formações diversas, especialistas (em pequeno número), mestres (as) e doutores (as). Os (as) demais são professores (as) substitutos (as), colaboradores (as) que auxiliam quando a demanda é maior; entretanto, todos (as) têm a preocupação em fazer desta formação um processo técnico, político e ético, incluindo aí a postura e ações para o desenvolvimento dos estágios, que são atividades curriculares obrigatórias em todos os cursos.

Vale destacar que os (as) professores (as) que fizeram parte na condição de formadores do PARFOR são de diversas faculdades que ofertaram cursos do Campus de Belém, onde temos a representação maior da UFPA, pois lá está o complexo que abriga a reitoria, pró-reitorias e demais órgãos responsáveis em garantir o seu funcionamento e 
dos demais campi que ficam nos municípios paraenses: Abaetetuba, Ananindeua, Altamira, Bragança, Breves, Cametá, Castanhal, Capanema, Salinópolis, Soure e Tucuruí.

Conforme o Projeto Pedagógico do Curso (PPC) de Licenciatura em Pedagogia da Faculdade de Educação e Ciências Humanas, do Campus Universitário do Marajó Breves (de onde falamos), os estágios curriculares estão organizados a partir do $5^{\circ}$ semestre para quem é do período extensivo diurno (março a junho/agosto a dezembro), assim como para os do período intensivo (janeiro e fevereiro/julho e agosto). Mas para quem é do noturno, o início do estágio ocorre no $6^{\circ}$ período, tendo em vista que a carga horária noturna é menor que a diurna e, por isso, precisam de nove semestres.

Na seção seguinte trataremos das experiências que temos nos estágios com essas turmas, indicando como são organizados, onde e como acontecem, em especial como os (as) futuros (as) pedagogos (as) fazem os registros e as socializações de suas experiências com essas atividades.

\title{
OS ESTÁGIOS NA FORMAÇÃO DE PROFESSORES NO CURSO DE LICENCIATURA EM PEDAGOGIA
}

De acordo com o Projeto Pedagógico do Curso de Licenciatura em Pedagogia da Faculdade de Educação do Campus Universitário do Marajó-Breves,

\begin{abstract}
o estágio supervisionado para o Curso de Pedagogia é considerado disciplina curricular, uma vez que antes da entrada do aluno no seu futuro espaço profissional, o mesmo terá que desenvolver atividades de sala de aula que embasarão a sua atuação nos diferentes espaços profissionais, assim como no término dos estágios, obrigatoriamente os alunos retornarão à sala de aula para apresentação de seus relatórios de atividades. Os estágios obrigatórios ocorrerão a partir do quinto semestre do curso, sendo distribuídos um por período para que haja maior tempo de planejamento e execução, assim como, melhor acompanhamento por parte do professor (a) orientador (a) das atividades desenvolvidas. Os não obrigatórios ficarão na responsabilidade de planejamento do (a) docente com a turma (PROJETO PEDAGOGICO DO CURSO DE PEDAGOGIA DO CUMB, 2011, p. 30).
\end{abstract}

Por ser um Campus considerado de pequeno porte ${ }^{6}$, o número de professores (as) da faculdade de Educação também é pequeno $0^{7}$ para dar conta de todas as demandas de atividades curriculares. $O$ (a) professor (a) que optar por trabalhar com uma das atividades curriculares de estágio será o (a) responsável por assumir uma turma que, em média, tem 35 acadêmicos. Esse (essa) professor (a) recebe a turma, entra em contato com as escolas campo de estágio - ainda não temos uma coordenação de estágio na faculdade -, organiza o planejamento e faz as orientações iniciais, quase sempre com duração de $12 \mathrm{~h}$, ou seja, 3 dias de aulas, para que todos (as) possam chegar ao seu campo com os devidos conhecimentos do que vai fazer e para onde vai. Além disso, há o planejamento que cada estagiário (a) deverá elaborar para dar conta das suas atribuições de acordo com cada estágio no campo da docência: Estágio Supervisionado (60h), Estágio Curricular na Educação de Jovens e Adultos (60h), Estágio Curricular em Docência na Educação Infantil 
(90h) e Estágio Curricular em Docência no Ensino Fundamental (90h). No Campo da gestão há o Estágio Curricular em Gestão na Escola e Coordenação Pedagógica (60h) e em Ambientes não escolares - Estágio Curricular em Ambientes Não-Escolares (45h).

Estágio Supervisionado: é o primeiro estágio em que o (a) futuro pedagogo (a) adentra com o propósito de conhecer o que é a instituição que tanto ouviu falar, depois de passar anos entrando e saindo dela como se a conhecesse em todas as suas nuances. Nesse estágio, seu olhar não poderá mais ser de "algo conhecido", mas de "estranhamento", olhar de pesquisador, de quem tem a responsabilidade de (des) construir conceituações, aproximações entre teoria e prática. Essa aproximação com o campo profissional é momento de reflexão e de análises das práticas institucionais e, a partir dessas reflexões, deve-se levantar dados com os "mais" experientes.

A metodologia proposta é a cartografia da escola, registrada em diários de estágios, a partir das dimensões da escola a serem investigadas e dos dias definidos para os estágios. A cartografia como metodologia, à qual nos referimos, vem ao encontro do que Filho e Teti (2013) apresentam como sendo uma ligação aos campos de conhecimento das ciências humanas e sociais.

\begin{abstract}
Mais que mapeamento físico, trata de movimentos, relações, jogos de poder, enfrentamentos entre forças, lutas, jogos de verdade, enunciações, modos de objetivação, de subjetivação, de estetização de si mesmo, práticas de resistência e de liberdade. Não se refere a método como proposição de regras, procedimentos ou protocolos de pesquisa, mas, sim, como estratégia de análise crítica e ação política, olhar crítico que acompanha e descreve relações, trajetórias, formações rizomáticas, a composição de dispositivos, apontando linhas de fuga, ruptura e resistência (FILHO e TETI, 2013, p. 47).
\end{abstract}

É com este objetivo que orientamos a realização da cartografia da/na escola. 0 (a) acadêmico (a) recebe carta de apresentação da instituição concedente de estágio, agenda as datas com a direção e coordenação para adentrar em campo. Em média para esse estágio são necessários 15 (quinze) dias dedicados à atividade, quase sempre alternados por conta da disponibilidade dos agentes educacionais que acompanham os (as) estagiários e deles (as) próprios (as), que fazem suas adequações aos dias e horários estabelecidos. No período indicado o(a) estagiário(a) vai conhecer os(as) profissionais da escola, os(as) alunos(as), o currículo, a infraestrutura, os recursos financeiros que chegam à escola, vai participar de reuniões administrativas e pedagógicas e de atividades extraclasse, seja a entrada dos(as) alunos(as) na instituição, o momento de intervalo recreio, a distribuição da alimentação escolar -, o desenvolvimento de um projeto, festas cívicas e outras datas comemorativas na escola, os jogos, ações que estão no currículo, mas que envolvem outras pessoas, além de professores e alunos, ou seja, todas as ações que se integram para formar a escola. Esta perspectiva adotada por nós é o estágio como pesquisa, pois comungamos da premissa, de que:

A pesquisa no estágio, como método de formação de futuros professores, se traduz de um lado, na mobilização de pesquisas que permitam a ampliação e análise de contextos onde os estágios se realizam; por outro lado, e em especial, se traduz na possibilidade de os estagiários desenvolverem postura e habilidades de pesquisador 
a partir das situações de estágios, elaborando projetos que lhes permitam ao mesmo tempo compreender e problematizar as situações que observam (PIMENTA e LIMA, 2011, p. 46).

Os resultados desse processo são registrados de diferentes maneiras: nos últimos anos (2017 e 2018) algumas turmas já produziram relatórios de estágio, documentários sobre as instituições, mostras por meio de pôster; em forma de artigos científicos, acompanhados de seus diários de estágios. Todos eles traduzem as palavras de Pimenta e Lima (2011), pois os documentos recebidos por nós, seja relatórios ou artigos, deixam transparecer as suas habilidades de pesquisadores (as). Muitos estagiários (as) elaboram seus projetos de trabalho de conclusão de curso a partir dessa inserção, outros (as) levantam questionamentos sobre situações que muitas vezes passam despercebidas pela gestão da escola, como foi o exemplo dado em uma roda de conversa (onde eu estava como orientadora do Estágio Supervisionado) com uma das turmas do ano de 2018, quando o trio ${ }^{8}$ fez a socialização das atividades.

De acordo com as narrativas e os escritos no artigo, esse trio optou por verificar nas atividades extraclasse como se dava o trabalho das cozinheiras e do pessoal de apoio (serviços gerais). Ficaram sensibilizados com a forma amorosa como essas pessoas se apresentavam para fazer a alimentação e se empenhavam para manter a limpeza da escola. Entretanto, a queixa deles estava na não escuta de suas reivindicações. Para eles, na escola só se ouve o que os (as) professores (as) dizem e o que está para além da sala de aula parece não ter importância.

Esses relatos de experiência que chegam às nossas salas de aula na formação de professores (as) nos chamam a atenção para a maneira como conduzimos o estágio. Se o (a) acadêmico (a) não tem uma sólida preparação para adentrar na instituição, como será capaz de formular referências para as práticas futuras? Se o processo persistir com o foco apenas no futuro campo profissional, onde estará a nossa contribuição como mediadores (as) de novas práticas? A nossa concepção é resumida nas palavras de Pimenta (2006, p. 68), quando ela diz que "introduzir o aluno na escola para observar o seu funcionamento, não o capacita para desvelar a complexidade desta". Dessa forma, reafirmamos a nossa premissa de estágio como pesquisa, pois é a pesquisa "o elemento fundamental para nos ajudar a reunir as informações e os dados significativos para a elaboração do conhecimento" (GHEDIN, OLIVEIRA e ALMEIDA, 2015, p. 56).

Os estágios em docência no ensino fundamental, sejam eles para crianças nos anos iniciais ou na modalidade de Educação de Jovens e Adultos, têm outra forma de organização, uma vez que a universidade não pode se impor ao currículo das instituições, mas sim respeitá-las dentro de seus planejamentos, e é nesse contexto que organizamos os nossos estágios. Os (as) acadêmicos (as) são orientados (as) no planejamento a produzirem seus planos de aulas de acordo com as diretrizes das escolas, garantindo autonomia em suas regências com o propósito de não reproduzirem os trabalhos feitos pelos(as) professores(as) titulares das turmas, mas de produzirem as suas aulas, fazendo a conexão entre as diretrizes da escola e os conhecimentos apreendidos na academia de práticas pedagógicas enquanto responsabilidade social.

Uma das características marcantes e que tem chamado a atenção dos(as) professores(as) titulares das turmas em relação aos(às) estagiários(as) centra-se na 
produção de um plano de aula que não se limita a trabalhar os conhecimentos cognitivos, mas planos de aulas onde se inserem temas transversais, que costuram os conhecimentos do currículo "tradicional" das escolas com as práticas culturais da nossa região, mostrando aos(às) alunos(as) que a escola não está desconectada da vida e nem pode estar distante de suas histórias. Dessa maneira, há necessidade da aproximação da intencionalidade das práticas pedagógicas em diálogo com os coletivos sobre os quais atua, conforme aponta Franco (2012).

Essa forma de produzir as regências - de acordo com os artigos que são produzidos por nossos(as) estagiários(as) - trazem duas situações de análises: uma está no elogio direcionado a eles/elas por muitos(as) professores(as) pela qualidade dos trabalhos desenvolvidos, já que muitas vezes nunca estiveram numa sala de aula como professores(as) e conseguem fazer com que crianças, jovens e adultos se interessem pelas aulas, mesmo com as poucas condições dadas aos(às) professores(as) pelo sistema municipal de ensino; outra, é a rejeição dos(as) estagiários (as) por alguns(mas) professores(as), que argumentam que estagiário(a), "só vem para falar mal da prática do professor titular", "para atrapalhar a turma, porque não conhecem os alunos e não sabem dar aulas", "para ficar acostumando mal os alunos porque depois querem aulas 'diferentes' e o estagiário só as faz porque não fica os 200 dias na escola", dentre tantas outras que fazem com que esse momento seja de controvérsias.

Entretanto, avaliamos que os estágios de regência-práticas pedagógicas realizados nas escolas não podem ser considerados sem as suas devidas dificuldades, mas não podemos ficar somente reclamando deles, precisamos avançar, imprimindo marcas de práticas pedagógicas planejadas por meio dos estágios, de acordo com o contexto social e cultural vivido, que venham ao encontro do conhecimento, que chega como expressão de um currículo que traz relações de poder e, por isso mesmo, deve ser questionado e posto em diálogo com todos aqueles(as) que o receberão, seja para o(a) professor(a) gestor da sala de aula ou para os(as) alunos(as) a quem cabe a responsabilidade de, a partir dele, produzir suas concepções de mundo.

As experiências aqui apresentadas não acontecem apenas no meio urbano. Como indicado neste texto, temos alunos (as) que moram em diferentes lugares, em particular os (as) que fazem o curso no período intensivo, alguns (mas) não moram na cidade, mas no meio rural, em vilarejos, conhecidos como comunidades, e nelas sempre há uma escola, além daqueles (as) que são de outros municípios. Para esses (as) acadêmicos (as) o desafio é maior: por estudarem no período intensivo, considerados férias ou recessos escolares, não podem fazer estágios concomitantemente ao período de aulas da faculdade e seus estágios são orientados nesse período para que no decorrer do semestre possam executá-los.

O problema dessa questão está na falta de acompanhamento direto do (a) professor (a) nas escolas onde os (as) estagiários (as) executarão seus trabalhos, são lugares diferentes e de longa distância entre eles. São muitos fatores que contribuem para que o(a) professor(a) não consiga acompanhá-los(as), dentre eles encontram-se as outras atribuições dos(as) professores(as), falta de transporte para chegar às comunidades ou recurso financeiro para pagar o deslocamento do(a) professor(a) a outro município, até porque a justificativa para o não pagamento está na matrícula do(a) aluno(a) que é no Campus de Breves, portanto, deveria fazer o estágio na cidade de Breves, mas, pelas condições sociais da região, ou produzimos estratégias para que eles façam os estágios 
onde moram, com algumas exceções, ou muitos não terão condições de concluir o curso. O Marajó é rico em fauna, flora, na generosidade de seu povo, mas muito carente financeiramente, faltam recursos para garantia de qualidade de vida. Nesses casos, acompanhamos os estágios de forma indireta, pelas redes sociais e e-mail, pois dificilmente uma comunidade não tem uma antena para captar o sinal de internet.

Os resultados são gratificantes pela riqueza de detalhes com que nos contam a realização de seus trabalhos, desde ter que atravessar rios, furos, ilhas, de canoa a remo, de rabetas ${ }^{9}$, barcos pequenos, ou mesmo de carona com o condutor do transporte escolar, para chegar a escola e encontrar ex-professores (as), ainda no mesmo lugar, continuando sua jornada no magistério, dando asas para que seus (as) alunos (as) possam voar e de repente pousar no mesmo lugar, mas agora com outras expectativas.

Há também aqueles (as) que já trabalham em outras funções nas escolas do campo e quanto voltam para essas escolas na condição de estagiários (as) e para as regências como professor (a), são muito bem recebidos (as), bem-vistos pela comunidade, que almeja ver seus (suas) filhos (as) ascendendo educacional e socialmente. É a universidade pública cumprindo o seu papel de socializar os conhecimentos, e o Campus de Breves cumprindo seus fins, dentre eles o de "formar e qualificar continuamente profissionais nas diversas áreas do conhecimento, zelando por sua formação humanística e ética, de modo a contribuir ao pleno exercício da cidadania, promoção do bem público e melhoria da qualidade de vida, particularmente da Amazônia" (Art. $6^{\circ}$ - II REGIMENTO GERAL DO CUMB, 2014).

Os estágios, com exceção dos que já pontuamos, acontecem nas escolas da cidade de Breves. Entretanto, a maioria das escolas de ensino fundamental está espalhada nas escolas do campo, no meio rural, entre os rios e a floresta. Dessa maneira, percebemos um hiato na formação dos (as) futuros (as) professores (as), ao considerarmos que, ao concluir essa formação, não haverá vagas disponíveis de trabalho apenas nas escolas da cidade; o mais provável, pelo número elevado de escolas, é que as vagas estarão no meio rural, onde há grandes diferenças no tipo de escola, no ensinar, nos métodos, nos meios, além de outras situações, conforme alerta Hage (2006, p. 3):

Os professores enfrentam uma sobrecarga de trabalho, sendo forçados a assumir outras funções, além da docência, a saber: faxineiro, líder comunitário, diretor, secretário, merendeiro, agricultor, agente de saúde, parteiro, etc. Eles também enfrentam interferências no trabalho advindas das secretarias de educação, como reflexo das relações políticas que envolvem o poder local, mudando constantemente de escola em função da instabilidade no emprego.

Nesse caso, podemos afirmar que o nosso curso com seus estágios não consegue abarcar essa diversidade de atribuições problematizadas por Hage (2006), que são exigidas do (a) professor (a). Mas para que não saiam da academia sem pelo menos ter uma amostra de como são essas escolas, elaboramos projetos para viagens, quase sempre em parceria com a secretaria de educação do município, já que o Campus não dispõe de transporte fluvial que caiba o quantitativo de alunos que temos por turma. Programamos 
a viagem para um tempo curto, pois é a condição que temos, saindo às $6 \mathrm{~h}$ e retornando às $18 \mathrm{~h}$. Nesse tempo temos a possibilidade de viajar pelos rios e conhecer algumas escolas, fazendo paradas em, pelo menos, duas delas, onde há o encontro do (a) acadêmico (a) com a comunidade local e educacional. Lá eles (elas) fazem perguntas aos comunitários, conhecem a escola e os espaços para o desenvolvimento do trabalho docente. Em alguns desses lugares não há nem alojamento para o (a) professor (a). Caso ele não seja do local, na maioria das vezes precisa receber apoio de uma família da comunidade que lhe ofereça estadia pelo tempo em que trabalhar na escola. Caso seja escola com mais de um (a) professor (a), eles (as) ficam juntos e dividem o mesmo espaço.

Os estágios de Gestão da Escola e Coordenação Pedagógica também seguem a mesma perspectiva de estágio, pois, como afirmam Pimenta e Lima (2011, p. 114),

a pesquisa é componente essencial das práticas de estágio, apontando novas possibilidades de ensinar e aprender a profissão docente, inclusive para os professores formadores, que são convocados a rever suas certezas, suas concepções do ensinar e do aprender e seus modos de compreender, de analisar, de interpretar os fenômenos percebidos nas atividades de estágio.

Um desses fenômenos, citados por Pimenta e Lima (2011), e que precisamos melhor interpretar, encontra-se na recepção que um bom número de professores(as) fazem aos estagiários(as), pois quando estão nessa condição reclamam da não receptividade dos(as) colegas e quando chegam à direção e coordenação pedagógica da escola fazem da mesma maneira, marcam horários e não cumprem, dizem que estão ocupados(as), mandam voltar depois e o mais intrigante: se negam a apresentar aos(às) estagiários(as)os recursos financeiros que chegam à escola, assim como o Projeto Político Pedagógico (PPP). Esses fatos, pelo menos nos nossos campos de estágios, são recorrentes, ou seja, em dez anos de experiências com estágios podemos dizer que tem escolas que continuam usando a mesma justificativa para não apresentar seu PPP, alegando que está em processo de reformulação. São inquietações que nos movem a outros questionamentos, o que é importante, já que sem elas não haveria produção de novos conhecimentos.

O estágio em Ambientes Não-Escolares tem outra dinâmica, não menos importante no processo de formação dos (as) pedagogos(as), mas não fará parte das experiências apresentadas neste trabalho. Nossa contribuição na discussão sobre estágios manteve-se na tentativa de pensar essa prática de formação como construção de um trabalho não só para a prática educativa, mas também para a prática social, a partir do conhecimento de múltiplas realidades e múltiplos contextos e dessa forma nos aproximar da qualidade de ensino almejada por todos (as).

\section{CONSIDERAÇÕES FINAIS}

Após breves análises do trabalho que realizamos nos estágios para a formação docente no curso de Pedagogia, podemos destacar, dentre outros pontos: os estágios desenvolvidos não fogem ao previsto nas legislações nacionais; e as características de ações em que os estágios são vistos como desvinculados de sua base teóricametodológica ainda podem ser encontradas em trabalhos, tanto na orientação de alguns 
professores (as), como nas atividades realizadas por alunos (as). Em particular, podemos apontar que os mais bem organizados sistematicamente como pesquisa vêm de alunos (as) que ainda não exercem o magistério, diferente de alguns (mas) que já exercem a profissão, que muitas vezes não fazem questão ou não conseguem fazer desconstruções para a prática reflexiva e renovada desse processo.

Consideramos que os estágios nos ajudam a reaprender a pensar, tanto para nós formadores (as) como para os (as) futuros (as) professores (as), em especial pelos desafios que cotidianamente enfrentamos, literalmente em atravessamentos, seja de barco, navio ou mesmo em pequenas lanchas que nos levam aos diferentes municípios do Marajó, onde temos turmas de licenciaturas.

Esses aprendizados e/ou conhecimentos adquiridos nos fazem a cada ano renovar nossas esperanças em uma formação que seja endereçada não só ao trabalho pedagógico na cidade, onde em poucos minutos podemos nos sentar em frente a um grupo de alunos (as) organizados (as) por séries/anos, mas onde quer que tenham pessoas em busca de escolarização, seja em ruas ou rios, nosso trabalho precisa ser pensado para outros sujeitos, com outras pedagogias. Afinal, como problematiza Arroyo (2014) "se os educandos são outros, a docência, os docentes poderão ser os mesmos?" Assim vamos orientando nossos estágios, visitando nossos campos, acompanhando os (as) estagiários (as), realizando a socialização dos conhecimentos produzidos, enfim, dando a nossa contribuição à educação por meio da formação docente, já que temos grandes responsabilidades em auxiliar na construção de identidades profissionais autônomas.

Artigo recebido em: 01/02/2019 Aprovado para publicação em: 20/05/2019

INTERNSHIPS IN THE TRAINING OF TEACHERS IN AMAZON MARAJOARA: EXPERIENCES OF THE PEDAGOGY COURSE OF THE UNIVERSITY CAMPUS OF MARAJÓ - BREVES

ABSTRACT: This article aims to present experiences of how to develop the compulsory internships in the undergraduate program in Pedagogy of the Federal University of Pará, Campus Universitário do Marajó - Breves. It is characterized as a qualitative research. As a theoretical basis for the analyzes, we chose the studies of Pimenta and Lima (2011), Franco (2012), Ghedin et al. (2015). The students who are part of this Campus, are from different municipalities of Marajó, urban and rural residents (riparians), which makes the internships become great challenges, both for academics, but also the results presented, indicate that the work carried out- between streets, rivers, and forests - goes from the perspective of internships as a source of research, helping in the formation of autonomous and reflective teachers about and from their socio-cultural and educational reality.

KEYWORDS: Internships. Teacher training. Experiences. Marajó. 
AMARAL, S. M. P. do

PASANTÍA EN LA FORMACIÓN DE PROFESORES (AS) EN LA AMAZONIA MARAJOARA: VIVENCIAS Y EXPERIENCIAS DEL CURSO DE PEDAGOGÍA DEL CAMPUS UNIVERSITARIO DEL MARAJÓ - BREVES

RESUMEN: El presente artículo tiene como objetivo presentar experiencias de cómo se desarrollan las etapas obligatorias en el curso de licenciatura en Pedagogía de la Universidad Federal de Pará, Campus Universitario del Marajó - Breves. Se caracteriza como una investigación de base cualitativa. Como base teórica para los análisis, elegimos los estudios de Pimenta y Lima (2011), Franco (2012), Ghedin et al. (2015). Los estudiantes que forman parte de este Campus, son de diferentes municipios de Marajó, habitantes del medio urbano y rural (ribereños), lo que hace que los estadios se conviertan en grandes desafíos, tanto para los académicos (as) , para los profesores, los orientadores (as), sin embargo, los resultados presentados, indican que los trabajos realizados - entre calles, ríos y bosques, caminan en la perspectiva de pasantías como fuente de investigación, auxiliando en la formación de profesores (as) autónomos y reflexivos sobre y desde su realidad sociocultural y educativa.

PALABRAS CLAVE: Etapas. Formación docente. Experiencias. Marajó.

\section{NOTAS}

1) O uso da divisão do Marajó em Marajó dos Campos e Marajó das Florestas vem da problematização de Pacheco (2006), para quem a diferença existente neste arquipélago não é extrema, entretanto, trata-se de uma região plural em suas práticas sociais, as quais expressam riquezas e pobrezas diferenciadas.

2) Breves é um dos 16 municípios que fazem parte do arquipélago marajoara, está distante de Belém a aproximadamente $200 \mathrm{~km}$ em linha reta. Sua população é de aproximadamente 100.000 pessoas, considerado o maior município do arquipélago e onde se encontram os órgãos públicos de referência estadual e federal.

3) Afuá, Anajás, Bagre, Breves, Cachoeira do Arari, Chaves, Curralinho, Gurupá, Melgaço, Muaná, Ponta de Pedras, Portel, Salvaterra, Santa Cruz do Arari, São Sebastião da Boa Vista e Soure.

4) Turmas com um único professor que reúnem até sete séries concomitantes, incluindo educação infantil e ensino fundamental (ver Hage, 2006).

5) Dados de pesquisa realizada por mim (não concluída), no período de 2010 a 2013, quando estive como coordenadora do PARFOR, nas turmas do Marajó.

6) De acordo com o relatório anual do CUMB - 2018, a instituição conta com apenas 48 professores para as 5 faculdades: Ciências Naturais, Letras, Matemática, Serviço Social e Pedagogia, sendo: 50\% doutores, $44 \%$ mestres e $6 \%$ especialistas. A esse número de professores somam-se mais 22 pessoas no corpo técnico-administrativo, para atender um total de 875 alunos, daí a nossa inferência de que somos ainda um Campus de pequeno porte.

7) São 14 professores no total, sendo que, desses, 4 estão licenciados para o doutorado, ficando apenas 10 para atender 238 alunos no ano de 2018.

8) No estágio supervisionado, geralmente organizamos em trio, pois é um estágio que demanda o conhecimento das diferentes dimensões da escola, sendo, portanto, um trabalho que necessita de diferentes olhares para melhor produção e sistematização dos conhecimentos.

9) Pequena canoa de madeira acoplada a um motor elétrico. Poderíamos dizer que fazem os serviços das motos nos nossos rios, que são as nossas estradas. 


\section{REFERÊNCIAS}

ARROYO, M. G. Outros Sujeitos, outras Pedagogias. Petrópolis, RJ: Vozes, 2014.

AMARAL, S.M.P. Narrativas Interculturais na Sala de Aula: Antropologia e Educação no Marajó (Breves-Pará). Tese (Doutorado) - Programa de Pós-Graduação em Antropologia (PPGA), Instituto de Filosofia e Ciências Humanas, Universidade Federal do Pará, Belém, 2018.

BRASIL. Lei de Diretrizes e Bases da Educação Nacional - LDB, 9.394 de 20 de dezembro de 1996.

BRASIL. Lei № 11.788 de 25 de setembro de 2008.

BRASIL. RESOLUÇÃO № 2, DE 1 DE JULHO DE 2015.

BREVES. Regimento do Campus Universitário do Marajó - Breves. Resolução n. 772 CONSUN, de 18.12.2017. Universidade Federal do Pará, Belém.

Breves. Relatório Anual do Campus Universitário do Marajó - Breves. Ano 2018.

FILHO, K. P; TETI, M. M.A Cartografia como método para as Ciências Humanas e Sociais. Barbarói, Santa Cruz do Sul, n. 38, p. 45-59, jan./jun. 2013.

FRANCO, M. A. do R. S. Pedagogia e Prática docente. São Paulo: Cortez, 2012.

GHEDIN, E; OLIVEIRA, E. S. de; ALMEIDA, W. A. de. Estágio com Pesquisa. São Paulo: Cortez, 2015.

HAGE, S. A. M. A realidade das escolas multisseriadas frente às conquistas na Legislação Educacional. In: REUNIÃO ANUAL DA ANPED, 29, 2006. Caxambu. Anais... Disponível em www.anped. org.br.

PACHECO, A. S. À margem dos "Marajós": Cotidiano, Memórias e Imagens da "CidadeFloresta" - Melgaço-Pa. Belém: Paka-Tatu, 2006.

PIMENTA, S. G. e LIMA, M. do S. L. Estágio e Docência. São Paulo: Cortez, 2011.

PIMENTA, S. G. O Estágio na Formação de Professores: unidade teoria e prática? São Paulo: Cortez, 2006. 
AMARAL, S. M. P. do

SÔnia Maria Pereira do Amaral: Licenciada em Pedagogia, Mestre em Comunicação, Linguagens e Cultura e Doutora em Antropologia. Professora do Curso de Licenciatura em Pedagogia da Universidade Federal do Pará - UFPA, Campus Universitário do Marajó Breves.

Orcid: https://orcid.org/0000-0003-1525-4372

E-mail:smpa40@yahoo.com.br

Este periódico utiliza a licença Creative Commons Attribution 3.0, para periódicos de acesso aberto (Open Archives Iniciative - OAI). 